\title{
A Study on the Default Supplemental Adjustment Factors of Progression Adjustment Factor Formula under Non-Lane Based Traffic Condition
}

\author{
Abdullah Al Farabi \\ a.al.farabi.buet@gmail.com \\ Department of Civil Engineering, University of Asia Pacific, Dhaka, Bangladesh \\ Tamal Chakraborty \\ tamalchakraborty0108@gmail.com \\ Bangladesh University of Engineering and Technology, Dhaka, Bangladesh
}

\begin{abstract}
A mathematical expression of supplemental adjustment factor $\left(\mathrm{f}_{\mathrm{PA}}\right)$ has provided a way to estimate Progression Adjustment Factor (P.F.) more accurately as the P.F. relies on the $f_{P A}$ value. The mathematical formula of $f_{P A}$ requires traffic parameters that need to be determined from the field survey. As non-lane based traffic behavior is significantly different from lane-based traffic, this study examines the applicability of the default fPA values of Highway Capacity Manual-2000 under the non-lane based traffic condition. Default values for all six Arrival Types (AT1 to AT6) are reviewed against an available mathematical expression. After performing statistical analysis on the collected data, it is found that the HCM-provided default $\mathrm{f}_{\mathrm{PA}}$ values for AT1, AT3, AT5 and AT6 are consistent with the mathematical expression. However, the supplemental factors for AT2 and AT4 are found to vary significantly from the default values. By considering the mathematical expression as a standard of comparison, a graphical representation of error corresponding to trial $\mathrm{f}_{P A}$ value shows that a value of 0.99 for $\mathrm{f}_{\mathrm{PA}}$ provides the minimum error of P.F. for AT2. Thus, the default value $\left(f_{P A}=0.93\right)$ is found to underestimate $f_{P A}$ as well as P.F. by $6.5 \%$. In a similar way, the $f_{P A}$ value for AT4 is found to be 0.96 which is $16.5 \%$ less than the default value. So, the default value $\left(\mathrm{f}_{\mathrm{PA}}=1.15\right)$ overestimates $\mathrm{f}_{\mathrm{PA}}$ and P.F. by $16.5 \%$. Therefore, $\mathrm{f}_{\mathrm{PA}}=0.99$ for AT2 and $\mathrm{f}_{\mathrm{PA}}=0.96$ for AT4 should be used to estimate P.F. in case of non-lane based traffic.
\end{abstract}

Keywords: Highway Capacity Manual; Progression Adjustment Factor; Default supplemental adjustment factor; Modified supplemental adjustment factor; Non-lane based traffic

\section{INTRODUCTION}

Highway Capacity Manual (TRB, 2000) provides a mathematical model of control delay which includes a factor termed as Progression Adjustment Factor (P.F.). In fact, from previous HCM (TRB, 1985) to the most updated version, this factor is recognized to incorporate the effects of signal progression on vehicle-delay estimation. This factor is also present in the Canadian Capacity Guide (ITE, 2008) which provided a model to estimate vehicle stops. Now, this P.F. factor includes a supplemental adjustment factor $\left(\mathrm{f}_{\mathrm{pA}}\right)$ in its expression. By addressing the six different Arrival Types (AT), (Akcelik, 1996) provided two distinct lists of the supplemental factors for the uniform delay and the overflow delay component. Later, (TRB, 2000) provided default values of 
supplemental adjustment factor $\left(\mathrm{f}_{\mathrm{pA}}\right)$ for six types of arrival (AT1 to AT6) of vehicles. (Strong \& Rouphail, 2005) analyzed and explained these $\mathrm{f}_{\mathrm{pA}}$ factors and they highlighted an underlying assumption that is associated with the HCM provided P.F. formula. Most importantly, they were able to formularize $\mathrm{f}_{\mathrm{pA}}$ mathematically by eliminating this assumption. Thus, this mathematical formula eliminates the need for using default $\mathrm{f}_{\mathrm{pA}}$ values. Again, another approach was taken by $(\mathrm{Wu}, 2014)$ to modify the Progression Adjustment Factor (P.F.) considering the planning aspects. (Wu, 2014) provided valuable insights into P.F. formulation for default conditions. Nonetheless, default supplemental values of HCM are still useful in determining performance indicators (delays, stops) and it can also be used in planning scenarios. So, the authors of this study have decided to focus on the mathematical expression developed by (Strong \& Rouphail, 2005). This expression provides mathematical ground to the $\mathrm{f}_{\mathrm{pA}}$ factor and the formula is more suitable than default HCM-provided values. However, the $\mathrm{f}_{\mathrm{pA}}$ formula requires two additional traffic parameters and these parameters need field determination. This aspect has motivated the authors to determine the $\mathrm{f}_{\mathrm{pA}}$ factors by performing field surveys and assess whether the default values agree with the HCM-provided values. The significance lies in the fact that the traffic condition in non-lane based operation is much different than lane-based disciplined traffic. So, any discrepancy in default values will lead to errors in stops and delay estimation. Besides, previous studies on control delays by (Hadiuzzaman et al., 2014) and (Farabi et al., 2018) used default values of the $\mathrm{f}_{\mathrm{pA}}$ factors to determine P.F. values. So, the significance is understandable as the default values might have led to errors in delay estimations. Therefore, considering the traffic conditions of the Dhaka city, the authors perform a study to justify whether the default values of HCM supplemental adjustment factor $\left(\mathrm{f}_{\mathrm{pA}}\right)$ provides accurate P.F. for different arrival types, or the mathematical expression by (Strong \& Rouphail, 2005) should be used. Also, an approach to modify the default values for non-lane based traffic conditions is taken if found necessary. Therefore, the rest of the paper explains the methods of the study and data collection. After that, a comparative analysis is provided in this study.

\section{METHODS OF THE STUDY}

Progression Adjustment Factor (P.F.) formula of Highway Capacity Manual (TRB, 2000) is shown in Equation (1).

$$
P \cdot F=\frac{(1-P) f_{p A}}{1-\frac{g}{C}}
$$

Where,

P.F. $=$ Progression Adjustment Factor

$\mathrm{P} \quad=\mathrm{R}_{\mathrm{P}} \frac{\mathrm{g}}{\mathrm{C}}=$ Proportion of vehicles in arrival in green

$\mathrm{R}_{\mathrm{P}}=$ Platoon Ratio

$\frac{\mathrm{g}}{\mathrm{C}}=$ Ratio of effective green to Cycle time

$\mathrm{f}_{\mathrm{pA}}=$ Default Supplemental Adjustment Factor

Equation (1) requires default Supplemental Adjustment Factor $\left(\mathrm{f}_{\mathrm{PA}}\right)$, which can be found in the HCM as shown in Table 1. 
Table 1: Default Supplemental Adjustment Factor $\left(\mathrm{f}_{\mathrm{PA}}\right)$ provided by HCM

\begin{tabular}{|c|c|c|c|c|c|c|}
\hline Arrival Type & AT1 & AT2 & AT3 & AT4 & AT5 & AT6 \\
\hline Progression Quality & \multirow{2}{*}{ Very Poor } & \multirow{2}{*}{ Non-Favorable } & Isolated & Favorable & \multirow{2}{*}{ Highly Favorable } & \multirow{2}{*}{ Exceptional } \\
\hline $\mathbf{P}_{\mathbf{A}}$ & $1 / 3$ & $2 / 3$ & 1 & $4 / 3$ & $5 / 3$ & 2 \\
\hline $\mathbf{f}_{\mathbf{p A}}$ & 1.00 & 0.93 & 1.00 & 1.15 & 1.00 & 1.00 \\
\hline
\end{tabular}

Table 1 lists the default $\mathrm{f}_{\mathrm{PA}}$ factors for six different arrival types. HCM determines and classifies the arrival types (AT1-AT6) using the Platoon Ratio formula $\left(\mathrm{R}_{\mathrm{P}}\right)$ and this classification of arrival types can be found in HCM. It can be observed from Table 1 that the $\mathrm{f}_{\mathrm{PA}}$ factors for AT1, AT3, AT5, AT6 are equal to unity. But, $\mathrm{f}_{\mathrm{PA}}$ factors for AT2 and AT4 are different from unity. At the same time, Table 1 shows the description of Progression quality and the Platoon arrival ratio $\left(\mathrm{P}_{\mathrm{A}}\right)$ for every arrival type. $\mathrm{P}_{\mathrm{A}}$ is the ratio of the arrival flow rate in green period $\left(\mathrm{v}_{\mathrm{G}}\right)$ to the arrival flow rate of the cycle $(\mathrm{v})$. The default values of $\mathrm{P}_{\mathrm{A}}$ for each arrival type are also provided by HCM.

On the contrary, (Strong \& Rouphail, 2005) provided a detailed expression of P.F. by eliminating the underlying assumption of HCM provided P.F. formula. They proved that the P.F. of HCM makes an assumption that the uniform queue dissipation happens at the same time position in a cycle irrespective of signal coordination. By eliminating this assumption, they provided a new formula of P.F. as shown in Equation (2).

$$
\mathrm{P} . \mathrm{F}=\frac{(1-\mathrm{P})}{\left(1-\frac{\mathrm{g}}{\mathrm{C}}\right)} * \frac{\left(1-\frac{\mathrm{v}}{\mathrm{S}}\right)}{\left(1-\mathrm{R}_{\mathrm{p}} * \frac{\mathrm{v}}{\mathrm{S}}\right)} *\left[1+\frac{\mathrm{v}}{\mathrm{S}} * \frac{\left(1-\mathrm{R}_{\mathrm{p}}\right)}{\left(1-\frac{\mathrm{g}}{\mathrm{C}}\right)}\right]
$$

Where,

P.F. $=$ Progression Adjustment Factor (P.F.)

$\mathrm{P}=\mathrm{R}_{\mathrm{P}} \frac{\mathrm{g}}{\mathrm{C}}=$ Proportion of vehicles in arrival in green $\left(\mathrm{R}_{\mathrm{P}}=\right.$ Platoon Ratio $)$

$\underline{\mathrm{g}} \quad=$ Ratio of effective green to Cycle time

$\mathrm{V}=$ Arrival flow rate (vehicles per hour)

$\mathrm{S}=$ Saturation Flow Rate (vehicles per hour)

So, Equation (2) provides an equation of P.F. which includes $\mathrm{f}_{\mathrm{PA}}$ as a multiplicative term instead of a default value. Therefore, $\mathrm{f}_{\mathrm{pA}}$ factor is expressed mathematically as shown in Equation (3).

$$
\mathrm{f}_{\mathrm{pA}}=\frac{\left(1-\frac{\mathrm{v}}{\mathrm{S}}\right)}{\left(1-\mathrm{R}_{\mathrm{p}} * \frac{\mathrm{v}}{\mathrm{S}}\right)} *\left[1+\frac{\mathrm{v}}{\mathrm{S}} * \frac{\left(1-\mathrm{R}_{\mathrm{p}}\right)}{\left(1-\frac{\mathrm{g}}{\mathrm{C}}\right)}\right]
$$

Equation (2) was derived analytically and it is superior to simplified HCM formula. It requires two additional traffic parameters (arrival flow rate and saturation flow rate) to determine P.F. Also, results given by Equation (2) are more precise than Equation (1). However, on the other hand, it is not sure how much accuracy the Equation (2) provides over Equation (1) in the case of non-lane based traffic.

It is obvious that non-lane based traffic is significantly different from lane-based 
traffic. With different compositions of vehicles in traffic stream, saturation flow rates in non-lane based traffic vary greatly. In addition, queue formation and queue discharge are quite different in non-lane based traffic. As vehicles form clusters near the intersection, they tend to utilize gaps to go faster during discharge. So, traffic parameters vary greatly and it is always preferable to determine the traffic parameters by performing site surveys in case of non-lane based traffic. As Equation (2) depends on the saturation flow that needs to be determined from the field, this formula should reflect the field conditions much better if used in the study.

Therefore, Equation (2) is considered as the basis of the study and an analysis to review the existing default $\mathrm{f}_{\mathrm{PA}}$ factors in comparison to Equation (2) was performed in this study. This comparison provides a justification for the applicability of HCMprovided default values. The above-mentioned procedure of the study is summarized in the general framework shown in Figure 1.

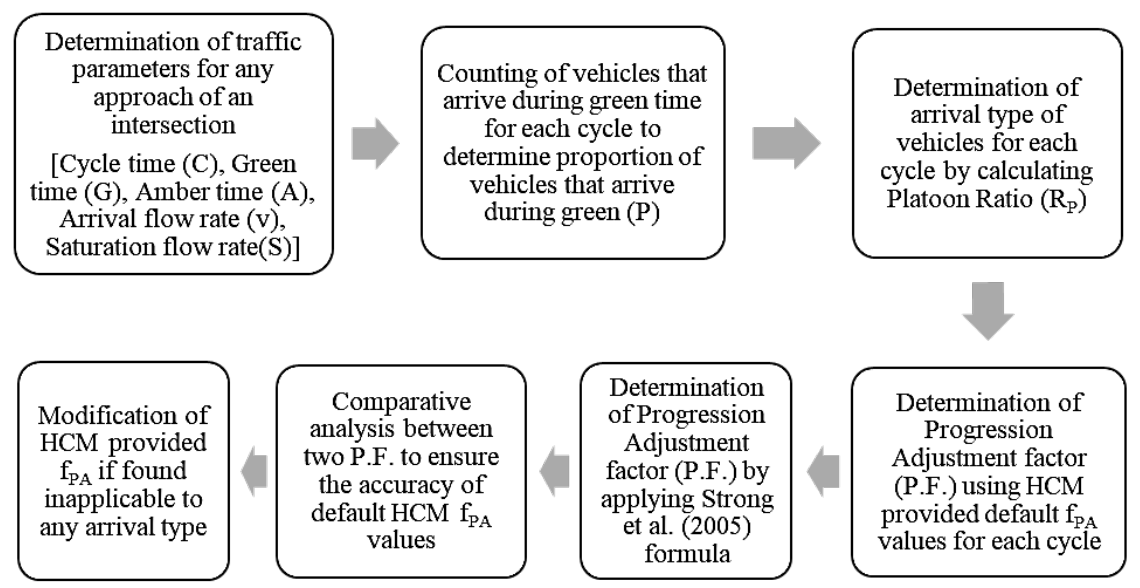

Figure 1: Procedures followed for the study

The procedure in Figure 1 requires various traffic parameters and those parameters were measured in the site. Cycle time, Green time, Amber time needs no special method as they were measured directly. Likewise, vehicle arrival flow and departure flow were performed by counting. Using the counting, arrival flow rate (v) was determined by following the method of (McShane et al., 1990), which is shown in Equation (4).

Average Arrival flow rate, $v=\frac{\text { vehicles passed in green }+ \text { queued vehicles at the end of green }}{\text { Cycle time }}$

Another important parameter is the saturation flow (S). Saturation flow rate $(\mathrm{S})$ and lost times were determined by Road Note 34 method (Webster, 1963). This method requires Passenger Car Equivalent (PCE) values to determine saturation flow rate. PCE values for this study were taken from (Hadiuzzaman et al., 2008). After determining the saturation flows (in units of PCU per hour) for each green period, it was converted into equivalent vehicles per hour using the procedure described in Canadian Capacity Guide (ITE, 2008) as presented in Equation (5). 
Where,

$$
\mathrm{S}_{\mathrm{veh} / \text { hour }}=\frac{\mathrm{S}_{\mathrm{PCU} / \text { hour }}}{\sum \frac{\mathrm{OP}_{\mathrm{k}} * \mathrm{a}_{\mathrm{k}}}{100}}
$$

$\% \mathrm{P}_{\mathrm{k}}=$ Percentage of vehicles in category $\mathrm{k}$ that arrive

$\mathrm{a}_{\mathrm{k}}=\mathrm{PCE}$ factor for vehicle type $\mathrm{k}$

\section{SITE SELECTION AND DATA COLLECTION}

Data for the study were collected from an urban intersection of Dhaka city known as "Hotel Intercontinental" intersection. This intersection is a three-legged intersection. Data were collected from all three approaches (East, North, and South) of the intersection. Video recording method was applied to collect primary data. Data were collected on three different days between 09:30 a.m.-11.00 a.m., 02.00 p.m.-05.00 p.m. and 02.30 p.m.-05.30 p.m. A total of 6 hours of recordings were analyzed.

Now, an important fact to notice about the selected intersection is that the traffic movements of the intersection are controlled manually by Police. As the upstream intersections of the "Hotel Intercontinental" intersection are also maintained manually, there is no proper coordination among the intersections. This fact leads to generation of various arrival types in any approach of the intersection. So, it is quite common to observe different arrival types in this intersection.

\section{COMPARATIVE ANALYSIS OF PROGRESSION ADJUSTMENT FACTORS}

After video data collection and data transcription from video recordings, Progression Adjustment Factor (P.F.) for each observation was determined. These values are summarized in Table 2 to Table 7.

Table 2: Progression Adjustment Factor for Arrival Type-1 (AT1)

\begin{tabular}{|c|c|c|c|c|c|c|c|c|}
\hline & \multicolumn{7}{|c|}{ Arrival Type-1 (AT1) } \\
\hline $\begin{array}{c}\text { Observation } \\
\text { No. }\end{array}$ & $\mathbf{g} / \mathbf{C}$ & $\mathbf{R p}$ & $\mathbf{P}$ & $\begin{array}{c}\mathbf{f}_{\mathbf{P A}} \\
\text { (Strong) }\end{array}$ & $\begin{array}{c}\text { P.F. } \\
\text { (Strong) }\end{array}$ & $\begin{array}{c}\mathbf{f}_{\mathbf{P A}} \\
\text { (HCM_Default) }\end{array}$ & $\begin{array}{c}\text { P.F. } \\
\text { using } \mathbf{f}_{\mathbf{P A}} \\
\text { (HCM_Default) }\end{array}$ & $\begin{array}{c}\text { Percentage } \\
\text { of deviation }\end{array}$ \\
\hline 1 & 0.15 & 0 & 0.00 & 1.43 & 1.16 & 1 & 1.17 & $\mathbf{0 . 9 4}$ \\
\hline 2 & 0.21 & 0 & 0.00 & 1.59 & 1.27 & 1 & 1.27 & -0.25 \\
\hline 3 & 0.13 & 0.3 & 0.28 & 1.22 & 1.11 & 1 & 1.11 & -0.04 \\
\hline 4 & 0.24 & 0.34 & 0.46 & 1.47 & 1.21 & 1 & 1.21 & 0.12 \\
\hline 5 & 0.16 & 0.47 & 0.29 & 1.26 & 1.1 & 1 & 1.11 & 0.77 \\
\hline 6 & 0.13 & 0 & 0.42 & 1.28 & 1.15 & 1 & 1.15 & -0.36 \\
\hline 7 & 0.26 & 0.3 & 0.42 & 1.53 & 1.26 & 1 & 1.25 & -0.7 \\
\hline 8 & 0.18 & 0.43 & 0.28 & 1.3 & 1.12 & 1 & 1.13 & 0.57 \\
\hline 9 & 0.15 & 0 & 0.36 & 1.48 & 1.15 & 1 & 1.17 & 2.01 \\
\hline 10 & 0.23 & 0.39 & 0.36 & 1.36 & 1.19 & 1 & 1.18 & -0.71 \\
\hline
\end{tabular}


Table 3: Progression Adjustment Factor Arrival Type-2 (AT2)

\begin{tabular}{|c|c|c|c|c|c|c|c|c|}
\hline & \multicolumn{9}{|c|}{ Arrival Type-2 (AT2) } \\
\hline $\begin{array}{c}\text { Observation } \\
\text { No. }\end{array}$ & $\mathbf{g} / \mathbf{C}$ & $\mathbf{R p}$ & $\mathbf{P}_{\mathbf{A}}$ & $\begin{array}{c}\mathbf{f}_{\mathbf{P A}} \\
\text { (Strong) }\end{array}$ & $\begin{array}{c}\mathbf{P . F .} \\
\text { (Strong) }\end{array}$ & $\begin{array}{c}\mathbf{f}_{\mathbf{P A}} \\
\text { (HCM_Default) }\end{array}$ & $\begin{array}{c}\text { P.F. } \\
\text { using } \mathbf{f}_{\mathbf{P A}} \\
\text { (HCM_default) }\end{array}$ & $\begin{array}{c}\text { Percentage } \\
\text { of deviation }\end{array}$ \\
\hline 1 & 0.4 & 0.76 & 0.75 & 1.01 & 1.18 & 0.93 & 1.08 & -8.08 \\
\hline 2 & 0.52 & 0.66 & 0.65 & 1.05 & 1.44 & 0.93 & 1.28 & -11.2 \\
\hline 3 & 0.57 & 0.82 & 0.80 & 1.05 & 1.3 & 0.93 & 1.16 & -11.11 \\
\hline 4 & 0.44 & 0.56 & 0.55 & 1.03 & 1.38 & 0.93 & 1.25 & -9.37 \\
\hline 5 & 0.59 & 0.81 & 0.79 & 1.05 & 1.33 & 0.93 & 1.18 & -11.05 \\
\hline 6 & 0.32 & 0.77 & 0.75 & 1 & 1.12 & 0.93 & 1.03 & -7.31 \\
\hline 7 & 0.41 & 0.84 & 0.83 & 1 & 1.11 & 0.93 & 1.04 & -6.76 \\
\hline 8 & 0.49 & 0.65 & 0.63 & 0.91 & 1.22 & 0.93 & 1.25 & 2.36 \\
\hline 9 & 0.32 & 0.78 & 0.75 & 0.89 & 0.98 & 0.93 & 1.03 & 4.69 \\
\hline 10 & 0.19 & 0.6 & 0.65 & 0.94 & 1.04 & 0.93 & 1.02 & -1.58 \\
\hline 11 & 0.2 & 0.66 & 0.62 & 1.19 & 1.08 & 0.93 & 1.01 & -6.74 \\
\hline 12 & 0.23 & 0.55 & 0.60 & 1.23 & 1.14 & 0.93 & 1.06 & -7.75 \\
\hline 13 & 0.14 & 0.53 & 0.46 & 1.15 & 1.07 & 0.93 & 1 & -7.06 \\
\hline 14 & 0.13 & 0.7 & 0.57 & 1.1 & 1.04 & 0.93 & 0.97 & -6.87 \\
\hline 15 & 0.14 & 0.52 & 0.42 & 1.21 & 1.06 & 0.93 & 1 & -5.82 \\
\hline
\end{tabular}

Table 4: Progression Adjustment Factor Arrival Type-3 (AT3)

\begin{tabular}{|c|c|c|c|c|c|c|c|c|}
\hline & \multicolumn{9}{|c|}{ Arrival Type-3 (AT3) } \\
\hline $\begin{array}{c}\text { Observation } \\
\text { No. }\end{array}$ & $\mathbf{g} / \mathbf{C}$ & $\mathbf{R p}$ & $\mathbf{P _ { \mathbf { A } }}$ & $\begin{array}{c}\mathbf{f}_{\mathbf{P A}} \\
\text { (Strong) }\end{array}$ & $\begin{array}{c}\text { P.F. } \\
\text { (Strong) }\end{array}$ & $\begin{array}{c}\mathbf{f}_{\mathbf{P A}} \\
\text { (HCM_Default) }\end{array}$ & $\begin{array}{c}\text { P.F. } \\
\text { using } \mathbf{f}_{\mathbf{P A}} \\
\text { (HCM_Defaut) }\end{array}$ & $\begin{array}{c}\text { Percentage } \\
\text { of deviation }\end{array}$ \\
\hline 1 & 0.43 & 1.01 & 1.00 & 1 & 0.99 & 1 & 0.99 & 0.11 \\
\hline 2 & 0.41 & 0.91 & 0.90 & 0.94 & 1 & 1 & 1.06 & 6.2 \\
\hline 3 & 0.45 & 1.08 & 1.07 & 1 & 0.93 & 1 & 0.93 & -0.07 \\
\hline 4 & 0.57 & 0.92 & 0.89 & 0.97 & 1.07 & 1 & 1.11 & 3.18 \\
\hline 5 & 0.15 & 0.88 & 0.79 & 1.04 & 1.02 & 1 & 1.02 & -0.07 \\
\hline 6 & 0.29 & 1.09 & 1.00 & 0.93 & 0.96 & 1 & 0.96 & 0.15 \\
\hline 7 & 0.54 & 0.92 & 0.75 & 1.13 & 1.11 & 1 & 1.09 & -1.52 \\
\hline 8 & 0.15 & 1.11 & 0.94 & 0.96 & 0.98 & 1 & 0.98 & -0.23 \\
\hline 9 & 0.33 & 1 & 0.93 & 1 & 1 & 1 & 1 & 0 \\
\hline
\end{tabular}

Table 5: Progression Adjustment Factor Arrival Type-4 (AT4)

\begin{tabular}{|c|c|c|c|c|c|c|c|c|}
\hline & \multicolumn{8}{|c|}{ Arrival Type-4 (AT4) } \\
\hline $\begin{array}{c}\text { Observation } \\
\text { No. }\end{array}$ & $\mathrm{g} / \mathrm{C}$ & $\mathbf{R p}$ & $\mathbf{P A}_{\mathbf{A}}$ & $\begin{array}{c}\mathbf{f}_{\mathbf{P A}} \\
\text { (Strong) }\end{array}$ & $\begin{array}{c}\text { P.F. } \\
\text { (Strong) }\end{array}$ & $\begin{array}{c}\mathbf{f}_{\mathbf{P A}} \\
\text { (HCM_Default) }\end{array}$ & $\begin{array}{c}\text { P.F. } \\
\text { using } \mathbf{f}_{\mathrm{PA}} \\
\text { (HCM Default) }\end{array}$ & $\begin{array}{l}\text { Percentage } \\
\text { of deviation }\end{array}$ \\
\hline 1 & 0.37 & 1.25 & 1.21 & 0.98 & 0.84 & 1.15 & 0.98 & 16.97 \\
\hline 2 & 0.22 & 1.4 & 1.23 & 0.78 & 0.88 & 1.15 & 1.02 & 14.96 \\
\hline 3 & 0.53 & 1.37 & 1.26 & 0.42 & 0.52 & 1.15 & 0.66 & 27.61 \\
\hline 4 & 0.42 & 1.34 & 1.29 & 0.62 & 0.73 & 1.15 & 0.87 & 19.12 \\
\hline 5 & 0.33 & 1.28 & 1.13 & 0.8 & 0.85 & 1.15 & 0.99 & 16.68 \\
\hline 6 & 0.16 & 1.23 & 1.11 & 0.9 & 0.96 & 1.15 & 1.1 & 14.73 \\
\hline 7 & 0.72 & 1.38 & 1.27 & 0 & 0 & 1.15 & 0 & 0.00 \\
\hline 8 & 0.52 & 1.29 & 1.18 & 0.55 & 0.64 & 1.15 & 0.79 & 22.93 \\
\hline
\end{tabular}


Table 6: Progression Adjustment Factor Arrival Type-5 (AT5)

\begin{tabular}{|c|c|c|c|c|c|c|c|c|}
\hline & \multicolumn{7}{|c|}{ Arrival Type-5 (AT5) } \\
\hline $\begin{array}{c}\text { Observation } \\
\text { No. }\end{array}$ & g/C & Rp & $\mathbf{P}_{\mathbf{A}}$ & $\begin{array}{c}\mathbf{f}_{\mathbf{P A}} \\
\text { (Strong) }\end{array}$ & $\begin{array}{c}\text { P.F. } \\
\text { (Strong) }\end{array}$ & $\begin{array}{c}\mathbf{f}_{\mathbf{P A}} \\
\text { (HCM_Default) }\end{array}$ & $\begin{array}{c}\text { P.F. } \\
\text { using f fA } \\
\text { (HCM_Default) }\end{array}$ & $\begin{array}{c}\text { Percentage } \\
\text { of deviation }\end{array}$ \\
\hline 1 & 0.08 & 1.77 & 1.60 & 1.02 & 0.95 & 1 & 0.93 & -1.85 \\
\hline 2 & 0.46 & 1.57 & 1.53 & 0.94 & 0.49 & 1 & 0.52 & 6.35 \\
\hline 3 & 0.19 & 1.58 & 1.30 & 0.75 & 0.86 & 1 & 0.86 & 0.05 \\
\hline 4 & 0.38 & 1.73 & 1.61 & 0.41 & 0.51 & 1 & 0.54 & 7.21 \\
\hline 5 & 0.3 & 1.78 & 1.71 & 0.51 & 0.63 & 1 & 0.66 & 3.75 \\
\hline 6 & 0.21 & 1.51 & 1.30 & 0.73 & 0.88 & 1 & 0.87 & -1.01 \\
\hline
\end{tabular}

Table 7: Progression Adjustment Factor Arrival Type-6 (AT6)

\begin{tabular}{|c|c|c|c|c|c|c|c|c|}
\hline & \multicolumn{7}{|c|}{ Arrival Type-6 (AT6) } \\
\hline $\begin{array}{c}\text { Observation } \\
\text { No. }\end{array}$ & $\mathbf{g} / \mathbf{C}$ & $\mathbf{R p}$ & $\mathbf{P}_{\mathbf{A}}$ & $\begin{array}{c}\mathbf{f}_{\mathbf{P A}} \\
\text { (Strong) }\end{array}$ & $\begin{array}{c}\mathbf{P . F} \\
\text { (Strong) }\end{array}$ & $\begin{array}{c}\mathbf{f}_{\mathbf{P A}} \\
\text { (HCM_Default) }\end{array}$ & $\begin{array}{c}\text { P.F. } \\
\text { using f } \mathbf{P A}_{\mathbf{A}} \\
\text { (HCM_Default) }\end{array}$ & $\begin{array}{c}\text { Percentage } \\
\text { of deviation }\end{array}$ \\
\hline 1 & 0.26 & 2.56 & 3.47 & 0.26 & 0.43 & 1 & 0.45 & 5.37 \\
\hline 2 & 0.27 & 2.25 & 2.00 & 0.4 & 0.52 & 1 & 0.55 & 4.75 \\
\hline 3 & 0.11 & 4.67 & 1.80 & 0.15 & 0.73 & 1 & 0.56 & -22.98 \\
\hline 4 & 0.12 & 2.11 & 3.45 & 0.7 & 0.86 & 1 & 0.85 & -0.6 \\
\hline 5 & 0.18 & 2.19 & 1.87 & 0.54 & 0.75 & 1 & 0.75 & -0.89 \\
\hline 6 & 0.18 & 2.5 & 1.85 & 0.41 & 0.67 & 1 & 0.66 & -1.46 \\
\hline
\end{tabular}

Table 2 to Table 7 shows the Progression Adjustment factor (P.F.) for all six-arrival types. Also, Platoon Arrival Ratio $\left(\mathrm{P}_{\mathrm{A}}\right)$ is shown for each observation. P.F. values were calculated using both the HCM-default $\mathrm{f}_{\mathrm{PA}}$ and Equation (2). The percentage of deviation of P.F. (by HCM) from the mathematical Equation (2) is shown in the last column of each Table (Table 2 to Table 7).

By analyzing Table 2, It is evident that the HCM formula estimates P.F. much accurately for AT1. The percentage of deviation from Equation (2) lies between $-0.71 \%$ to $2.01 \%$ for AT 1 . The average deviation is still less than $1 \%$. Therefore, the default HCM value agrees with Equation (2). For AT3, AT5, and AT6, the average deviation of $\mathrm{HCM}$ formula is much less than $5 \%$. At the same time, the deviations for these Arrival Types (AT3, AT5, and AT6) are not statistically significant. Therefore, the default HCM values for these arrival types agree with Equation (2).

For AT2, P.F. of HCM deviates from Equation (2) and the deviation ranges between $-11.2 \%$ to $4.69 \%$ as shown in Table 3 . The average deviation is $-6.24 \%$ with a standard deviation of $4.67 \%$. By performing a t-test, it is also found that this deviation is statistically significant. Therefore, HCM formula underestimates P.F. by $6 \%$. On a different note, the average $\mathrm{P}_{\mathrm{A}}$ value for the data of AT2 is 0.66 with a standard deviation of 0.12 . The average $P_{A}$ value is found to be equal with the listed value $\left(P_{A}=2 / 3\right)$ of Table 1 .

Data for AT4 is shown in Table 5. Observation No. 7 in Table 5 provides a zero value of P.F. for both the cases. This is due to the fact that all of the vehicles arrived during the green time. Thus, the proportion of vehicles arriving in green was equal to unity. This unity led to a zero value of P.F. in HCM formula. On the other hand, $\mathrm{f}_{\mathrm{pA}}$ value using Equation (2) is nearly zero. However, the P.F. still becomes zero as the $\mathrm{P}$ value was unity. Now, In the case of AT4, the average value of $\mathrm{P}_{\mathrm{A}}$ for the data is 1.21 with a standard 
deviation of 0.07 . The average value of $\mathrm{P}_{\mathrm{A}}$ is found to be lower than the listed value $\left(\mathrm{P}_{\mathrm{A}}=\right.$ 4/3) of Table 1.

The average deviation of P.F. is $16.5 \%$ with a standard deviation of $8.01 \%$ as shown in Table 5. This deviation is statistically significant enough. So, the HCM formula measures $16.5 \%$ higher value than Equation (2).

It is not quite sure about the exact reasons behind the significant differences from the default values of HCM for AT2 and AT4. However, $f_{P A}$ values for AT2 and AT4 are found to provide inaccurate results. Thus, these two values will lead to significant errors in the P.F. calculation. So, a further investigation on the data of AT2 and AT4 is performed to find appropriate values. A trial process is considered and a graph is plotted as shown in Figure 2.

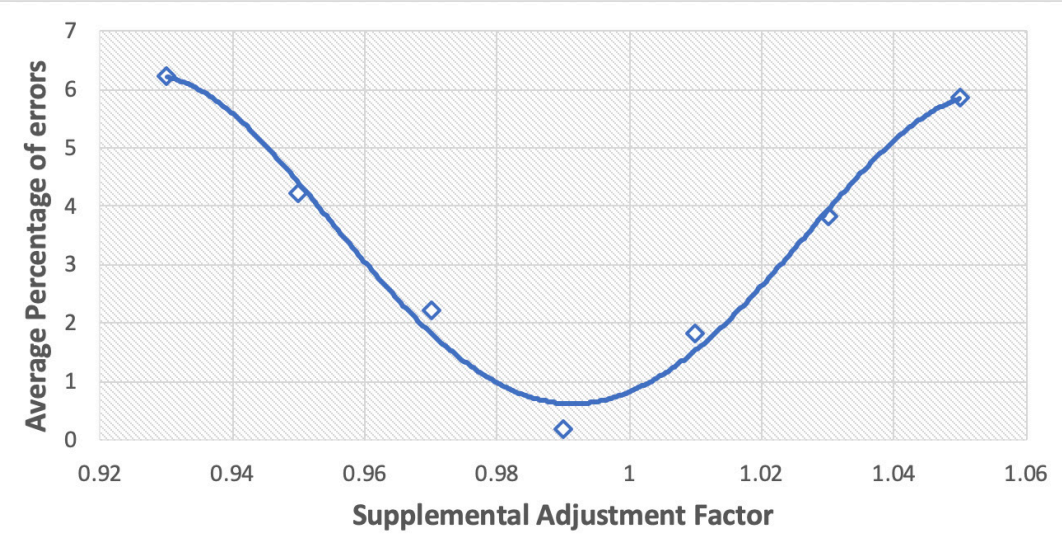

Figure 2: Modification of Supplemental Adjustment Factor Arrival Type 2 (AT 2)

Figure 2 depicts the average of the percentage of errors (deviation from Equation 2 is considered as error) corresponding to trial $\mathrm{f}_{\mathrm{PA}}$ values for AT2. The process of formulating the graph is as follows: a trial value of $\mathrm{f}_{\mathrm{PA}}$ is picked (a substitute of the HCM-provided $f_{P A}$ value) and P.F. is calculated for every observation with this trial value (Using the observations of Table 3). Thus, trial P.F. values are found for every observation. These trial P.F. values are then compared with the corresponding actual P.F. of Equation (2). From these comparisons, the percentage of errors were calculated for each observation (similar to the last columns of Table 2-7). Using the percentages, the average of the percentage of errors is determined. For different trial $\mathrm{f}_{\mathrm{PA}}$ values, this process is repeated. Lastly, a graph of error corresponding to trial $\mathrm{f}_{\mathrm{PA}}$ value is plotted which is shown in Figure 2.

Figure 2 clearly shows that the percentage of error is minimum at the value of 0.99 (rounded to two decimals). The error increases in both directions from the value of 0.99 . Therefore, the default value of $\mathrm{f}_{\mathrm{PA}}$ should be considered as 0.99 for AT2 instead of 0.93. A similar plot is drawn for Arrival Type 4 using the observations of Table 5 and it is shown in Figure 3. 


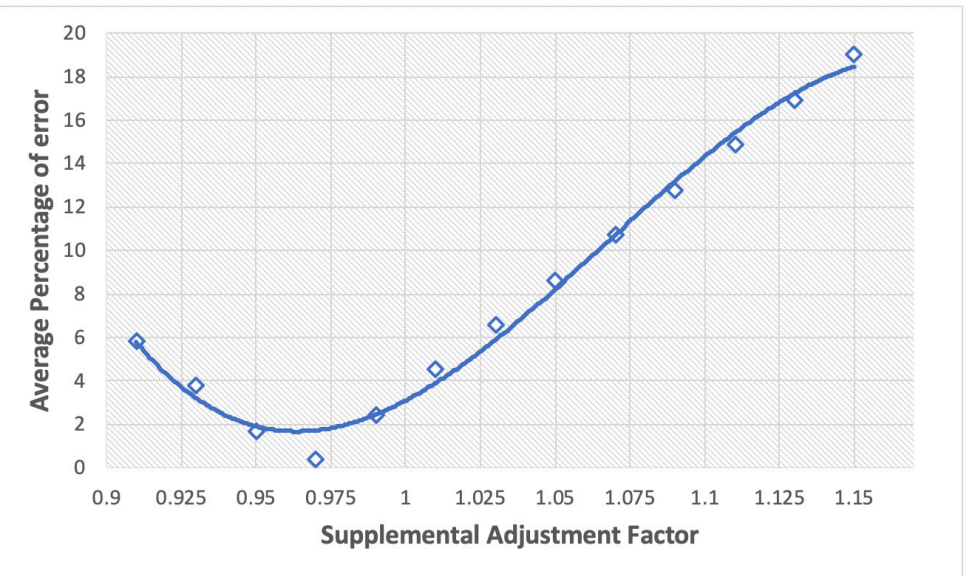

Figure 3: Modification of Supplemental Adjustment Factor Arrival Type 4(AT4)

It can be inferred from Figure 3 that the minimum percentage of error lies between 0.95 to 0.975 . By performing mathematical operation on the regressed curve, it is found that the minimum value should be considered as 0.96 for AT4 instead of 1.15.

\section{CONCLUSION AND RECOMMENDATIONS}

The comparative analysis concludes that the supplemental adjustment factors for Arrival Type 1, Arrival Type 3, Arrival Type 5, Arrival Type 6 of HCM (TRB, 2000) are acceptable. In other words, supplemental adjustment factors for these arrival types (AT1, AT3, AT5, AT6) can be used instead of the complex formula of Equation (2). On the other hand, factors for Arrival Type 2 and Arrival Type 4 have been found to deviate from the exact mathematical expression. Therefore, the modified values may be used instead of HCM-provided values. Therefore, the findings of the study are summarized in Table 8 which shows the updated supplemental adjustment factors.

Table 8: Supplemental Adjustment Factor $\left(f_{\mathrm{p} A}\right)$ provided by this study

\begin{tabular}{|c|c|c|c|c|c|c|}
\hline Arrival Type & AT1 & AT2 & AT3 & AT4 & AT5 & AT6 \\
\hline fPA & 1.00 & $\underline{\mathbf{0 . 9 9}}$ & 1.00 & $\underline{\mathbf{0 . 9 6}}$ & 1.00 & 1.00 \\
\hline
\end{tabular}

Table 8 provides the values of Supplemental Adjustment Factor $\left(\mathrm{f}_{\mathrm{PA}}\right)$ that can be used in non-lane based traffic condition. However, this study is based on a single intersection of Dhaka city. More extensive research is still necessary to get the exact reasons behind the deviations. More data will eventually lead to accurate determinations of supplemental Adjustment Factors. However, the findings of this study are much useful and significant when estimating performance indicators such as delay, vehicle stops, queue length, etc. So, this study will eventually lead towards accurate determinations of Progression Adjustment Factor (P.F.) in case of non-lane based traffic. 


\section{REFERENCES}

Akçelik, R. (1996). Progression Factor for Queue Length and Other Queue-Related Statistics. Transportation Research Record, 1555(1), 99-104.

Farabi, A. A., Hadiuzzaman, M. \& Hoque, M. S. (2018). A study on The Effect of Non-Lane Behaviour on HCM 2000 Delay Formula, In Proceedings of 4th International Conference on Advances in Civil Engineering ICACE, CUET. Chittagong, 887-892.

Hadiuzzaman, M., Rahman M. M. \& Karim M. A. (2008), Saturation Flow Model at Signalized Intersection for Non-Lane Based Traffic. Canadian Journal of Transportation, Volume 2, Part 1, page 77-90.

Hadiuzzaman, M., Rahman, M., Hasan, T. \& Karim, M. A. (2014). Development of Delay Model for Non-Lane Based Traffic at Signalized Intersection. International Journal of Civil Engineering, 3, 67-82.

ITE (2008). Canadian Capacity Guide for Signalized Intersections. Ed. J W Gough (Canada: Institute of Transportation Engineers).

McShane, W. R., Roess, R. P. \& Prassas, E. S. (1990). Traffic Engineering. International Edition, Pearson Education International.

Strong, D. W. \& Rouphail, N. M. (2005). Incorporating the Effects of Traffic Signal Progression into the Proposed Incremental Queue Accumulation (IQA) Method. Compendium of Papers on TRB 2005 CD-ROM, Transportation Research Board, Washington D.C.

Transportation Research Board (TRB) (1985). Highway Capacity Manual. National Research Council, Washington, D.C.

Transportation Research Board (TRB) (2000). Highway Capacity Manual. National Research Council, Washington, D.C.

Webster, F. V. (1963). A Method of Measuring Saturation Flow at Traffic Signals. Road Research Laboratory, Road Note 34, Crowthrone.

$\mathrm{Wu}$, N. (2014). Modifying Progression Adjustment Factor and Upstream Filtering Adjustment Factor at Signalized Intersections in HCM. In TRB 2014 Annual Meeting, Preprint No. 140414. Transportation Research Board, Washington, D.C. 